\title{
Programmable Thermocouple Transmitter with Compensation Function
}

\author{
Ying-Li WANG ${ }^{a}$, Jian WANG ${ }^{\text {b, }}$, Zhuo-Zhi YAN \\ Harbin University of Science and Technology Harbin, China \\ awwrx90251@126.com, ${ }^{b} 529044399 @ q q . c o m$ \\ ${ }^{*}$ Corresponding author
}

Keywords: Cold-junction Compensation, Thermocouple.

\begin{abstract}
On the basis of discussing cold junction compensation of thermocouple measurement, an improving solution was provided which was based on the stm32 with the programmable thermocouple transmitter with compensation function. Thermo emf is sent to the MCU of the host computer after A/D conversion, and then a digital compensative algorithm realized through compensative algorithm in the MCU. Tests show that the system is accuracy and stable.
\end{abstract}

\section{Introduction}

At present, the temperature controller is widely used in industrial and agricultural production, scientific research and other fields. In the future the intelligent thermostat develops towards high precision, multi-function standardized bus and high reliability. This can be attributed to its low-cost, easy availability, high precision and stability of output for a wide temperature range. Known from the temperature measurement principle of thermocouple, only when the thermocouple cold junction temperature remains unchanged, the thermo emf is the single-valued function of the measured temperature. In the application, the cold junction temperature is easily affected by the fluctuation of the ambient temperature; the cold junction temperature is difficult to hold invariableness, so the thermocouple needs Cold Junction Compensation ${ }^{[1]}$.

While most of the thermocouple cold junction compensators are for a single type of thermocouple. So this paper proposes an approach that the compensator is designed to meet all kinds of thermocouples through programming.

\section{Principle}

Operating principle of thermocouples is based on Seebeck effect, which states that temperature difference between two different conductors or semiconductors will cause voltage difference between the two substances. The potential generated is caused by two different potentials which are contact potential and thermoelectric potential of single conductor.

\section{Contact Potential}

When two different metals A and B are connected, it will get a stable contact potential.

$$
\mathrm{E}_{\mathrm{AB}}(\mathrm{T})=\frac{\mathrm{kT}}{\mathrm{e}} \ln \frac{\mathrm{n}_{\mathrm{A}}}{\mathrm{n}_{\mathrm{B}}}
$$

$\mathrm{E}_{\mathrm{AB}}^{\prime}$ is contact potential of two metal materials $\mathrm{A}$ and $\mathrm{B}$ at temperature $\mathrm{T}$; $\mathrm{k}$ is Boltzmann's coefficient; $e$ is the amount of electronic charge; $n_{A}$ and $n_{B}$ are free electron density of the metal material $\mathrm{A}$ and $\mathrm{B}$. 


\section{Thermoelectric Potential of Single Conductor}

For a homogeneous metal conductor, if temperatures of the two sides are different, then the potential which is called thermoelectric potential of single conductor is generated. It can be as below:

$$
\mathrm{E}_{\mathrm{A}}\left(\mathrm{T}, \mathrm{T}_{0}\right)=\int_{\mathrm{T} 0}^{\mathrm{T}} \sigma_{\mathrm{A}} \mathrm{dT}
$$

$\sigma_{\mathrm{A}}$ is Thomson coefficient.

The potential is only related to the thermoelectric material and the two junction temperature (Fig.2.1). So the thermocouple thermal potential is

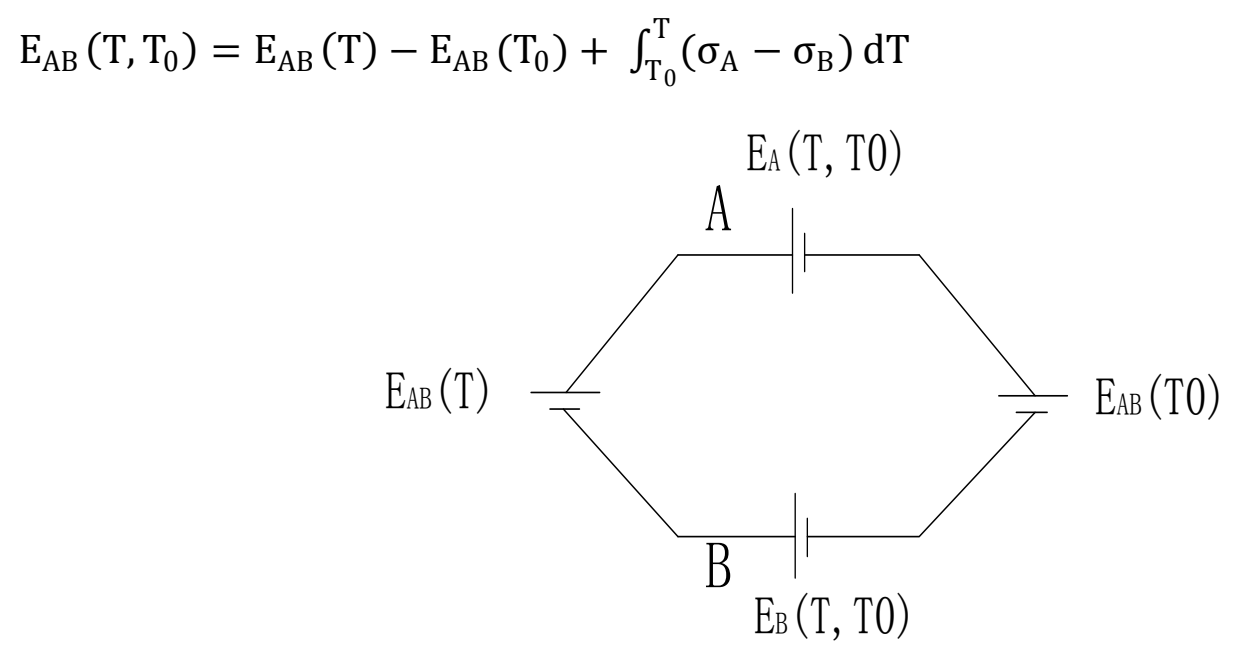

Fig.2.1

\section{Law of Intermediate Metal Law of Connecting Conductor}

When measuring temperature by thermocouple, the measuring instrument and connecting wire should be linked into the measuring circuit. In thermocouple circuit, as long as the temperature at both ends of the middle conductor is equal, the total potential of thermocouple circuit is not affected after connecting intermediate conductor to circuit.

Law of connecting conductor states that if the hot electrode $\mathrm{A}$ and $\mathrm{B}$ are respectively connected to the wire $A^{\prime}$ and $B^{\prime}$, the junction temperature respectively are $\mathrm{T}, \mathrm{T}_{\mathrm{n}}$ and $\mathrm{T}_{0}$, then the circuit potential will be the algebra sum of $\mathrm{E}_{\mathrm{ab}}\left(\mathrm{T}, \mathrm{T}_{\mathrm{n}}\right)$ and $\mathrm{E}_{\mathrm{a}}{ }^{\prime} \mathrm{b}^{\prime}\left(\mathrm{T}_{\mathrm{n}}, \mathrm{T}_{0}\right)$.

\section{Cold Junction Compensation Status}

At present, the most commonly used method of thermocouple cold-junction compensation has cold junction constant temperature method, bridge compensation method and cold junction temperature correction method.

(1) Bridge compensation method. Bridge compensation method is to use the electric potential generated by the unbalanced bridge to compensate the thermoelectric power changed value caused by the temperature of cold junction.

(2) Cold junction constant temperature method. The cold junction is placed in the ice water mixture to keep $0^{\circ} \mathrm{C}$. This method is of high precision, but it is inconvenient in the engineering.

(3) Cold junction temperature correction. Although the compensation wire can be used to extend the cold junction of the thermocouple to a constant temperature, as long as the temperature of the 
cold junction is not equal to $0^{\circ} \mathrm{C}$, the temperature measuring instrument indication value must be corrected. Currently the products which are based on the cold junction temperature correction are applied in a single type ${ }^{[2]}$.

\section{Programmable Temperature Compensation System}

This paper will introduce the programmable thermocouple temperature transmitter with compensation function which includes micro-processor module, signal acquisition module, SD module, keystroke and display module, output interface circuit module and power module (Fig.4.1).

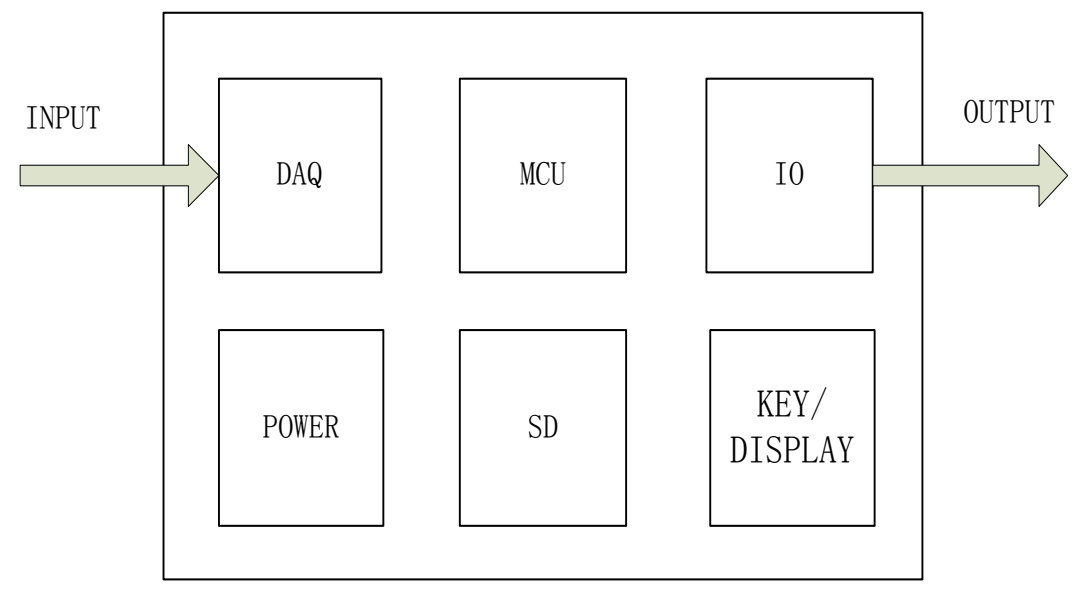

Fig.4.1 Module Chart

The electronic signal which is generated by temperature difference is sent to the thermocouple transmitter for compensation. First of all, the thermocouple output signal is amplified, filtered, AD converted and delivered into the MCU. Then MCU will select the temperature compensation table from the SD module in accordance with the setting. Finally MCU will process the signals with temperature compensation table in the SD card according to the principle of compensation. We can provide input interface and display interface on the peripheral equipment of the system to select the type and the range. After compensation, the signal will be DA converted and exported through the IO module. The whole system is a semi-closed system, which only provides a thermocouple signal input, a compensated signal output, a SD storage information updating interface port, and an external button setting and display part. The function of the interface design is simple and clear, and the design of semi-closed can also reduce external interference, so that it is safe and reliable.

\section{Micro-processor Module}

This system adopts 32-bit stm32f103ze based on Cortex-M3 as the control core. It offers a 32-bit product range while maintaining full integration and ease of development. And support SD card. And an extensive range of enhanced I/Os. All devices offer three 12-bit ADCs. The STM32F103ZE operates in the -40 to $+105^{\circ} \mathrm{C}$ temperature range, from a 2.0 to $3.6 \mathrm{~V}$ power supply to ensure the stable operation of the whole system.

\section{Signal Acquisition Module}

The analog acquisition circuit comprises an operational amplifier, filter and the reference temperature sensor. Thermocouple output potential signal is put into the operational amplifier (AD620) after filtering, and the amplified signal is delivered into the controller for AD conversion. 
The AD620 is a low cost, high accuracy instrumentation amplifier that requires only one external resistor to set gains of 1 to 10000. Furthermore, the AD620 offers lower power, making it a good fit for battery-powered portable applications. The AD620, with its high accuracy of 40ppm maximum nonlinearity, low offset voltage of $50 \mu \mathrm{V}$ max, and offset drift of $0.6 \mathrm{~V} /{ }^{\circ} \mathrm{C}$ max, is ideal for use in precision data acquisition systems.

\section{SD Module}

The SD module is used to store various types of thermocouple indexing table and other important information so as to realize the software compensation for temperature measurement. The main advantage of the SD flash is keeping the information to prevent accidental loss of data when the power is outage and supporting hot plug to realize the real-time data update.

\section{Keystroke and Display Module}

The keystroke is used to set the thermocouple parameters and the output range. There are four buttons which includes menu button, enter button, up button and down button which are used to set up parameters. The display module shows the information related to the settings.

\section{Output Interface Circuit Module}

After compensation, the analog output signals including the current (4-20mA) and voltage signals $(0-5 \mathrm{~V})$ are output in accordance with output range. Voltage signal is output by DAC of MCU and then the voltage signal is converted to the current signal $4-20 \mathrm{~mA}$ by the specific chip to simplify the output interface and to be convenient to the subsequent application.

\section{Power Module}

The power module is responsible for providing power to the entire system and two terminal operational amplifier.

\section{Small Deviation Linearization Method}

Small deviation linearization method is practical for the most working condition of the control system. In fact, automatic control system is always under normal circumstances called as the equilibrium state. Once the controlled value changed and made the bias, the control system began working in order to reduce or eliminate this bias. Therefore, the bias of the controlled quantity is generally not very big, only small deviation. So we can make small deviation linearization for nonlinear system.

\section{Software Algorithm}

We can make the thermocouple indexing table in accordance with the small deviation linearization method. The specific operations include simple addition, multiplication and look-up instructions.

(1) The thermocouple curve $E_{a b}(T, 0)$ is nonlinear as shown in Figure4.2. According to accuracy requirements, the $\mathrm{T}$-axis will be divided into $\mathrm{k}$ segments, and from the curve we can find the temperature of $T_{0}, T_{1}, T_{2} \ldots T_{k-1}$ and the corresponding value of thermoelectric power of $E_{0}, E_{1}, E_{2} \ldots E_{k-1}$ to create Table 1 . 


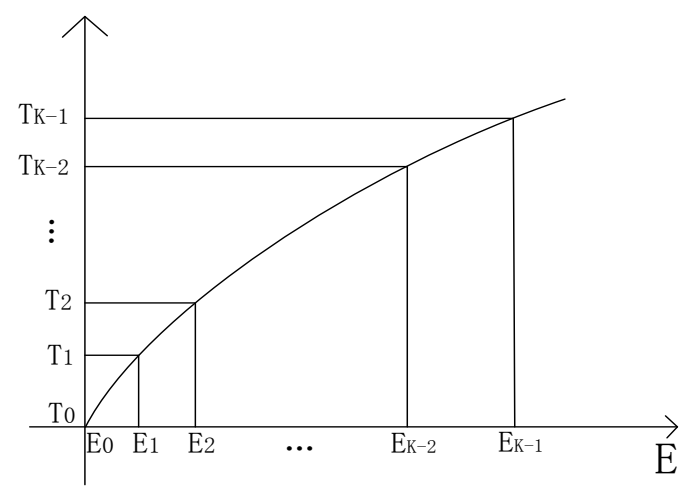

Fig.4.2

Tab.1 Actual Voltage and Temperature Diagram

\begin{tabular}{|c|c|}
\hline Temperature $\left[{ }^{\circ} \mathrm{C}\right]$ & Electric Potential [V] \\
\hline \multirow{2}{*}{$\mathrm{T}_{0}$} & $\mathrm{E}_{0}$ \\
\cline { 2 - 2 } & $\mathrm{K}_{0}$ \\
\hline \multirow{2}{*}{$\mathrm{T}_{1}$} & $\mathrm{E}_{1}$ \\
\cline { 2 - 2 }$\ldots$ & $\mathrm{K}_{1}$ \\
\hline \multirow{2}{*}{$\mathrm{T}_{\mathrm{K}-1}$} & $\cdots$ \\
\cline { 2 - 2 } & $\mathrm{E}_{\mathrm{k}-1}$ \\
\hline
\end{tabular}

(2) When $T=T_{x} \in\left(T_{0}, T_{1}\right)$

$\mathrm{K}_{0}=\frac{\mathrm{E}_{1}-\mathrm{E}_{0}}{\mathrm{~T}_{1}-\mathrm{T}_{0}}$

$\mathrm{E}_{\mathrm{x}}=\mathrm{K}_{0}\left(\mathrm{~T}_{\mathrm{x}}-\mathrm{T}_{0}\right)+\mathrm{E}_{0}$

(3) After the potential $\mathrm{E}\left(\mathrm{T}, \mathrm{T}_{0}\right)$ is measured, the corresponding thermoelectric power $\mathrm{E}\left(T_{0}, 0\right)$ is obtained by Table 1 in accordance with the cold junction temperature.

(4) Calculate formula

$$
\mathrm{E}\left(\mathrm{T}, 0^{\circ} \mathrm{C}\right)=\mathrm{E}\left(\mathrm{T}, \mathrm{T}_{0}\right)+\mathrm{E}\left(\mathrm{T}_{0}, 0\right)
$$

(5) Create Table 2 and get the corresponding temperature $\mathrm{T}$ by $\mathrm{E}(\mathrm{T}, 0)$ according to the thermocouple indexing table (free end temperature is $0^{\circ} \mathrm{C}$ ). The below is the T style table.

Tab. 2 Copper Constantan Thermocouple Indexing Table (the Free End Temperature of $0^{\circ} \mathrm{C}$ ) Index Number T

\begin{tabular}{|c|c|c|c|c|c|}
\hline $\begin{array}{c}\text { Working end } \\
\text { temperature }\end{array}$ & 0 & 1 & 2 & 3 & $\ldots$ \\
\hline-10 & -0.383 & -0.421 & -0.459 & -0.496 & $\ldots$ \\
\hline 0 & -0.000 & -0.039 & -0.077 & -0.116 & $\ldots$ \\
\hline 0 & 0.000 & 0.039 & 0.078 & 0.147 & $\ldots$ \\
\hline 10 & 0.391 & 0.430 & 0.470 & 0.510 & $\ldots$ \\
\hline$\ldots$ & $\ldots$ & $\ldots$ & $\ldots$ & $\ldots$ & $\ldots$ \\
\hline
\end{tabular}


Each type of thermocouple has two tables Table 1 and Table 2. Table 1 is a linear compensation table, and Table 2 is a thermocouple indexing table. The addresses of the Table 1 and Table 2 are encapsulated into a variable, and then each type of variable address is stored in a total address table. And a number represents a type. SD storage structure is as shown in the following Fig.4.3.

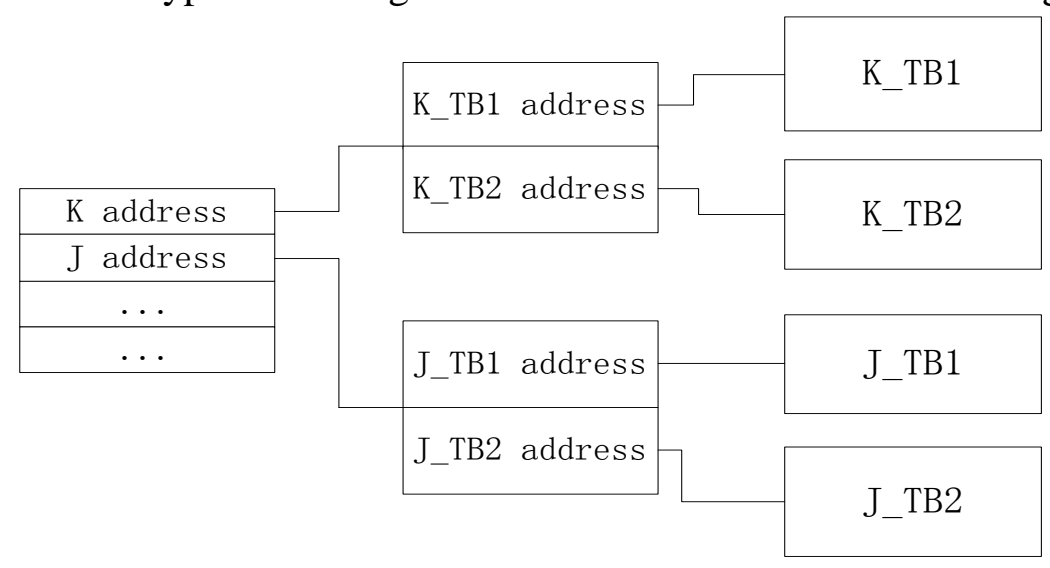

Fig. 4.3

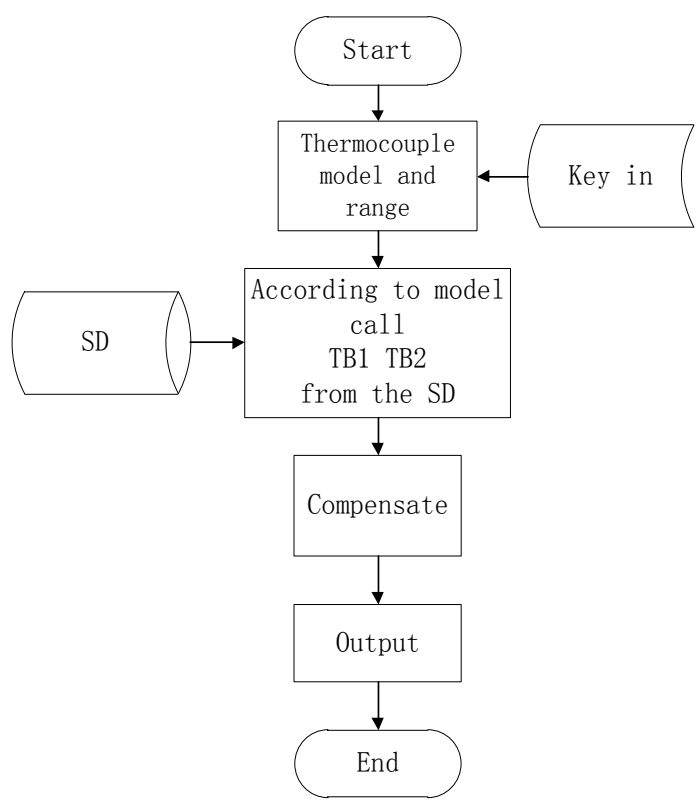

Fig.4.4

The steps to make the compensation are as shown in Fig.4.4.

\section{Conclusions}

Programmable thermocouple transmitter with compensation function can well meet the needs of cold junction compensation. At the same time programmable compensation system compared with the traditional compensation system has the following advantages: Programming: one compensator can be programmed to compensate for various types of thermocouples. Encapsulation: engineers only need to know how to use the interface, not to understand the internal structure. Encapsulation makes the system safe and reliable. Current output: the system provides current output which can easily be used to measure and protect the whole circuit. 


\section{Acknowledgement}

This research was financially supported by Natural Science Foundation of Heilongjiang Province of China (General Program) (E201235).

\section{Reference}

[1] Liu Fuliang. Experiment and Research on Cold Junction Compensation of Thermocouple [D]. BEIJING, North China Electric Power University, 2009.

[2] QIAN Jin. Cold-junction Compensation and Signal Linearization of Thermocouple Temperature Sensor [J]. Journal of Changjiang Engineering Vocational College, 2004, 21(2):32-34.

[3] HUANG Yi, ZHOU Hanyi, TAO Qingdong, LI Yun. Cold Junction Compensation in Thermocouple Thermometers [J]. Electronic Sci. \&Tech., 2015, 28(10):145-147.

[4] ZHANG, Hai-tao, LUO Shan, GUO Tao. Improvement of Cold-conjuntion Compensation of Thermocouple [J]. Instrument Technique and Sensor, 2011, (10):11-14.

[5] D. A. Lampasi, L. Podesta. A Measurement System Exploiting Non-Linearity of Thermocouples for Cold Junction Compensation [J]. IMTC2004-Instrumentation and Measurement Technology Conference, 2004: 2170-2175.

[6] Zhao Biao, She Jun. Research and Design of Cold Junction Compensation in Thermocouple Temperature Measurement [J]. JOURNAL OF SHANGHAI SHIP AND SHIPPING RESEARCH INSTITUTE, 2013, 36(1):50-53. 